\title{
Coordination of Group Movements in Wild Red-fronted Lemurs (Eulemur rufifrons): Processes and Influence of Ecological and Reproductive Seasonality
}

\author{
Lennart W. Pyritz • Peter M. Kappeler • \\ Claudia Fichtel
}

Received: 21 January 2011 / Accepted: 2 August 2011 /Published online: 9 November 2011 C) The Author(s) 2011. This article is published with open access at Springerlink.com

\begin{abstract}
Group-living species have to coordinate collective actions to maintain cohesion. In primates, spatial movements represent a meaningful model to study group coordination processes across different socio-ecological contexts. We studied 4 groups of red-fronted lemurs (Eulemur rufifrons) in Kirindy Forest, Madagascar, between 2008 and 2010 across different ecological and reproductive seasons. We collected data on ranging patterns using GPS collars and observational data on different predefined parameters of group movements, including initiation, leadership, followership, overtaking events, termination, and travel distances. Cohesion of these relatively small, egalitarian lemur groups was high year-round, but daily path length and home range size varied considerably between ecological seasons, presumably due to long-distance migrations of some groups at the beginning of the rainy season. Individuals of different age and sex classes successfully initiated group movements. However, stable female leadership prevailed year-round, irrespective of ecological and reproductive season, which might be due to higher or more specific energetic requirements of reproduction. In contrast to lemur species with a more despotic social structure, female red-fronted lemurs did not recruit more followers than males. Adult leaders recruited more followers than subadult ones. Further, recruitment success was higher during the peak of the dry season, when predation risk appeared to be higher. Distances of single group movements did not depend on the initiator's sex and age or on ecological seasons. Our results provide new insights into seasonal variability of coordination processes and the role of social dominance in lemur group movements, thereby contributing to a comparative perspective from a primate radiation that evolved group living independently of anthropoids.
\end{abstract}

L. W. Pyritz $(\bowtie) \cdot$ P. M. Kappeler $\cdot$ C. Fichtel

Behavioral Ecology \& Sociobiology Unit, German Primate Center, 37077 Göttingen, Germany e-mail: LennartPyritz@gmx.net

L. W. Pyritz $\cdot$ P. M. Kappeler $\cdot$ C. Fichtel

CRC "Evolution of Social Behaviour", University of Göttingen, 37077 Göttingen, Germany 
Keywords Cohesion · Eulemur rufifrons · Followership · Leadership · Overtaking

\section{Introduction}

Living in groups offers a number of individual benefits, including reduced per capita predation risk through shared vigilance or predator confusion (Bertram 1978), as well as opportunities to cooperate with kin, e.g., in the context of resource defense (Wrangham 1980). However, group living is also associated with costs because it requires consensus decisions to coordinate collective actions and to maintain cohesion, both prerequisites for the maintenance of stable social units (Conradt and Roper 2003; King et al. 2008). In the last few years, a large body of work on consensus decision making has been published comprising both theoretical (Conradt and Roper 2003, 2005) and empirical studies (Jacobs et al. 2011; Kerth et al. 2006; King et al. 2008; Sueur and Petit 2008a,b). The concept of leadership has also attracted much attention (King et al. 2009; Lewis et al. 2011; Rands et al. 2003, 2008; Stueckle and Zinner 2008). In contrast, only few studies have explored in detail the processes underlying coordinated collective actions from initiation to termination (Trillmich et al. 2004) and their socio-ecological determinants (Pyritz et al. 2011).

Most group-living species have to move regularly between different foraging patches and sleeping sites. During traveling, groups must stay cohesive despite interindividual conflicts of interests due to differences in motivation, knowledge, or physiological requirements (Conradt and Roper 2005). Therefore, spatial movements represent a salient and meaningful model to explore empirical and theoretical aspects of group coordination (Kappeler 2011; Petit and Bon 2010). In fact, most empirical studies so far have investigated group coordination in the context of collective movements (Bousquet et al. 2010; Jacobs et al. 2011; Ramseyer et al. 2009; Sueur and Petit 2008a,b; Trillmich et al. 2004). Further, large-scale ranging behavior and thus home range sizes of many species are strongly affected by ecological seasonality (Brockman and van Schaik 2004; Doran 1997; Scholz and Kappeler 2004), which raises the question of whether and how coordination processes of single group movements are also subject to seasonal changes.

Because ranging patterns and interindividual conflicts among group members vary according to resource availability, predation risk, or behavioral seasonality (Doran 1997; Isbell et al. 1990; Koenig 2002; Li et al. 2000), coordination processes should also depend strongly on these parameters. However, comprehensive studies on group coordination covering different socio-ecological seasons are lacking for primates. For instance, studies of different taxa revealed that rank, sex, age, experience, or residence patterns can be defining characteristics of leaders of group movements (Fichtel et al. 2011; King et al. 2009). One possible reason for male leadership is mating competition. For example, male mountain gorillas (Gorilla gorilla berengei) initiate group movements after contact with a rival (Watts 1994), and male spider monkeys (Ateles geoffroyi) frequently lead their group to the edge of the home range presumably to make contact with females from other groups (Chapman 1990). On the other hand, female leadership has been attributed to higher energetic needs of females because of gestation and lactation or superior knowledge 
of resource availability as a result of female philopatry (Boinski 1988, 1991; Erhart and Overdorff 1999; Trillmich et al. 2004). Because reproduction in many primate species is seasonal (Lindburg 1987), studies should cover reproductive and nonreproductive phases to disentangle potential effects of sex, physiological condition, social dominance, residence patterns, or experience on leadership (Trillmich et al. 2004).

An important first step in this direction is the description of fundamental coordination processes, i.e., which individuals initiate and lead group movements, how many group members follow in which time frame, how far the group travels, and which individual terminates the movement (Trillmich et al. 2004). A leader has been defined as an individual that exerts social influence on group members and elicits follower behavior (King 2010; Petit and Bon 2010; Pyritz et al. 2011). In principle, leadership can be distributed over several/all group members or 1 individual can lead the group consistently (Conradt and Roper 2005; King et al. 2008; Stueckle and Zinner 2008). Leadership in the context of group movements is labeled stable if overtaking during traveling occurs rarely, and as unstable if the leading individual routinely changes within 1 travel event (Pyritz et al. 2011). To describe group movements fully, it is important to study both which individuals initiate and lead and how many group members follow and the termination of group movements, because animals face 2 decisions during group movements: 1) when to go and in which direction and 2) where to stop. Thus, it is equally informative to focus on regularities in the termination of group movements (Trillmich et al. 2004; Pyritz et al. 2011).

We here investigated ranging patterns (home range sizes and daily path lengths) and coordination processes (leadership, overtaking, followership, and distances) in movements of 4 groups of wild red-fronted lemurs (Eulemur rufifrons) throughout a complete annual cycle. Our focal species provides a valuable model in this context for reasons having to do with their ecology, reproduction, social structure, and evolutionary history.

\section{Ecology and Seasonality}

The focal groups are free-ranging and coreside with a number of different predators (Pyritz and Andrianjanahary 2010; Rasoloarison et al. 1995), which should theoretically provide the necessary level of selective pressure favoring group cohesion, coordination and consensus decision making (cf. Fichtel et al. 2011b). The habitat is also strongly seasonal (Sorg and Rohner 1996), and earlier studies revealed pronounced seasonal variation in ranging behavior according to resource availability, including extraordinary seasonal migrations to places several kilometers outside their usual home range (Kappeler 2000; Overdorff 1993; Scholz and Kappeler 2004). In addition, red-fronted lemurs reproduce seasonally and give birth during the peak of the dry season (Wimmer and Kappeler 2002). Hence, these individuals offer the possibility to study effects of ecological variability and related variation in ranging behaviour, as well as reproductive seasonality on coordination processes. We predicted that daily path length should be longer during the dry season owing to larger distances between scattered resources (Anderson 1981). We also assumed that female leadership should prevail, at least during times of gestation and lactation 
because of increased energetic demands (Erhart and Overdorff 1999; Trillmich et al. 2004).

\section{Social Structure}

Most primate species studied so far in coordination research exhibit (relatively) strong dominance hierarchies, e.g., baboons (King et al. 2008) and macaques (Sueur and Petit 2008a,b; cf. Jacobs et al. 2008, 2011), whereas red-fronted lemurs live in small groups characterized by a relatively egalitarian social structure (Kappeler 1991; Pereira and McGlynn 1997). Many previous primate studies showed rank to be a determinant of leadership: white-faced capuchins (Cebus capucinus: Boinski 1993), ringtailed lemurs (Lemur catta: Sauther and Sussman 1993), mountain gorillas (Watts 1994), and chacma baboons (Papio ursinus: King et al. 2008), suggesting that social structure has a pervasive impact on coordination processes. Given the lack of clear dominance hierarchies in red-fronted lemurs, we expected at least occasionally successful initiations by members of different sex and age classes (Jacobs et al. 2008).

\section{Evolutionary History}

Living in bisexual groups evolved at least twice independently among Malagasy lemurs and only once among the ancestral anthropoids (Kappeler 1999), on which most coordination studies have been conducted to date (Boinski and Campbell 1995; Stewart and Harcourt 1994; Stueckle and Zinner 2008). Several lemur studies have explored predominantly acoustic coordination mechanisms in solitary and pair-living species that form sleeping groups: golden brown mouse lemurs (Microcebus ravelobensis: Braune et al. 2005), Milne Edwards' sportive lemurs (Lepilemur edwardsi: Rasoloharijaona et al. 2006), sportive lemurs (Lepilemur spp.: MéndezCárdenas et al. 2008), and red-tailed sportive lemurs (Lepilemur ruficaudatus: Fichtel and Hilgartner in press). Further, studies on a captive group of brown lemurs (Eulemur fulvus fulvus) provided insights into leadership and decision making during collective movements (Jacobs et al. 2008, 2011). Finally, 2 short-term studies have focused on coordination processes during movements of free-ranging groups: Milne-Edwards'sifakas (Propithecus edwardsi) and red-fronted lemurs (Erhart and Overdorff 1999) and Verreaux's sifakas (Propithecus verreauxi: Trillmich et al. 2004). However, studies exploring coordination in group-living lemurs through different socio-ecological seasons are entirely lacking. Therefore, our study also provides comparative data on the convergence of coordination in primate groups in their natural habitat from an evolutionary perspective.

\section{Methods}

\section{Study Site and Subjects}

We conducted this study at the field station of the German Primate Center (DPZ) at Kirindy Forest, a dry deciduous forest located $c a .60 \mathrm{~km}$ north of Morondava, 
western Madagascar (Sorg et al. 2003), managed within a forestry concession operated by the Centre National de Formation, d'Etudes et de Recherche en Environnement et Foresterie (CNFEREF). The habitat is characterized by pronounced seasonality with a hot rainy season between November and March and a cooler dry season between April and October (Sorg and Rohner 1996). During the dry season, groups of red-fronted lemurs make daily forays of $\leq 2 \mathrm{~km}$ to reach ephemeral water holes in the Kirindy River (Scholz and Kappeler 2004; Fig. 1). Reproduction of the species is seasonal, with a 4-week mating season in May-June and a birth season in September-October followed by a 4-mo lactation period (Barthold et al. 2009; Ostner and Kappeler 1999). Red-fronted lemurs face a number of predators at Kirindy, including fossas (Cryptoprocta ferox), harrier hawks (Polyboroides radiatus), stray dogs (Canis familiaris), and Malagasy ground boas (Acrantophis madagascariensis) (Fichtel and Kappeler 2002; Pyritz and Andrianjanahary 2010; Rasoloarison et al. 1995). The focal population inhabits a 60ha area within the forest featuring a grid system of narrow foot trails with intersections every $25 \mathrm{~m}$ or $50 \mathrm{~m}$ (Fig. 1). Individuals of all focal groups have been regularly captured, marked with unique nylon or radio collars, and observed since 1996 (Ostner and Kappeler 2004; Wimmer and Kappeler 2002). We marked infants with nylon collars 5-6 mo after birth and counted them as independent group members only from then on (Table I). Therefore, we were able to identify all focal individuals rapidly and reliably during observations in the field. Further, individual life histories and (maternal) relatedness were known for most individuals in our focal groups (Table I).

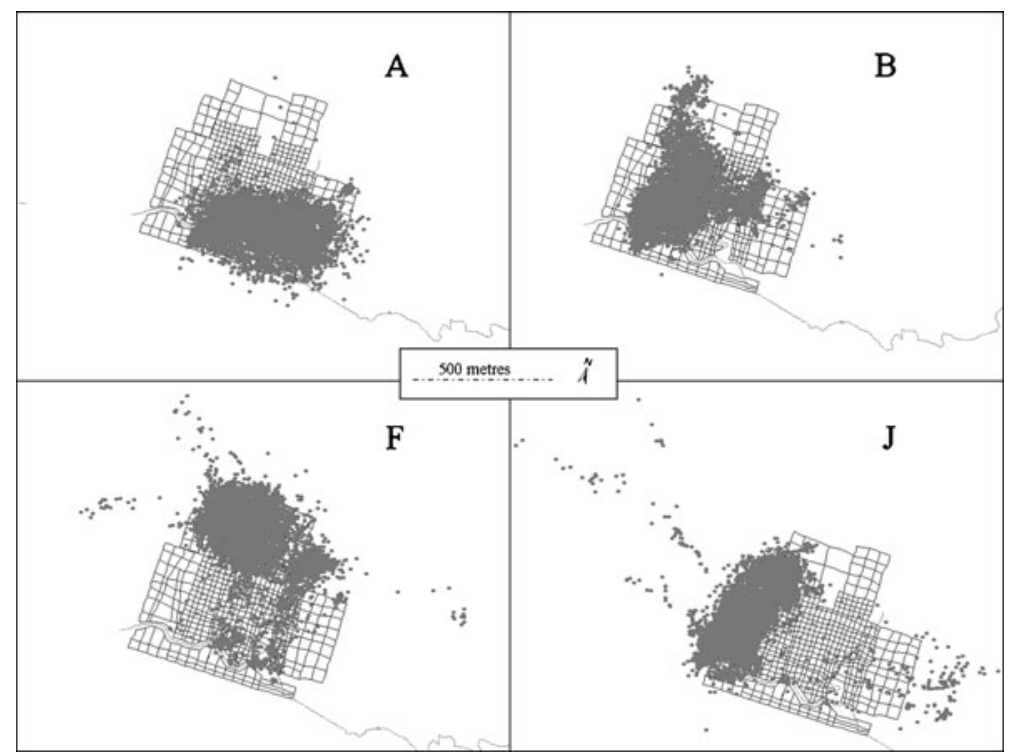

Fig. 1 GPS points of the 4 focal groups (A, B, F, J) collected between March 2008 and September 2009 on a map of the grid system at Kirindy Forest. The Kirindy River is depicted by the dotted line to the south of the study site. We present raw GPS data instead of MCP or kernel estimates to highlight single excursions of the groups that led to pronounced differences among different seasons and estimates (Table I). 
Table I Group composition, home range size, and mean daily path lengths throughout the study period

\begin{tabular}{lllllll}
\hline Group ID $\quad$ Sex $\begin{array}{l}\text { Age } \\
\text { class }\end{array}$ & $\begin{array}{l}\text { Natal to } \\
\text { group? }\end{array}$ & $\begin{array}{l}\text { Parents } \\
\text { known? }\end{array}$ & $\begin{array}{l}\text { Time in } \\
\text { group }^{\mathrm{a}}\end{array}$ & $\begin{array}{l}\text { Home range size } \\
(\mathrm{AK} / \mathrm{FK} / \mathrm{MCP}) \\
{[\mathrm{ha}]^{\mathrm{b}}}\end{array}$ & $\begin{array}{l}\text { Mean }( \pm \mathrm{SD}) \text {, } \\
\text { min and max } \\
\text { daily path } \\
\text { length }[\mathrm{m}]^{\mathrm{b}}\end{array}$ \\
\hline
\end{tabular}

\begin{tabular}{|c|c|c|c|c|c|c|c|c|}
\hline \multirow[t]{18}{*}{ A } & Cor & $\mathrm{F}$ & A & Unknown & Unknown & Whole study period & Rainy season: & Rainy season: \\
\hline & Pia & $\mathrm{F}$ & A & Yes & Both & Whole study period & AK: 19.1 & Mean: 1997 (507) \\
\hline & Sar & $\mathrm{F}$ & A & Yes & Both & Since May 2008 & FK: 18.6 & Min: 478 \\
\hline & Gig & M & A & No & Unknown & Until May 2008 & MCP: 53.8 & Max: 2792 \\
\hline & Gor & M & $\mathrm{A}$ & No & Unknown & Since Apr 2009 & & \\
\hline & Kos & M & $\mathrm{A}$ & No & Unknown & Until May 2008 & Dry season: & Dry season: \\
\hline & Lev & M & $\mathrm{A}$ & Yes & Both & Until May 2008 & AK: 19.0 & Mean: 1943 (484) \\
\hline & Pax & M & A & No & Unknown & Since Apr 2009 & FK: 18.5 & Min: 186 \\
\hline & Sam & M & $\mathrm{A}$ & No & Unknown & Until Feb 2010 & MCP: 59.2 & Max: 3752 \\
\hline & Sky & M & A & No & Unknown & Since Sept 2008 & & \\
\hline & Tho & M & A & No & Unknown & Since Apr 2009 & & \\
\hline & For & $\mathrm{F}$ & $\mathrm{J}$ & No & Both & May-Jun 2008 & & \\
\hline & $\mathrm{Pla}$ & $\mathrm{F}$ & $\mathrm{J}$ & Yes & Mother & Since Mar 2009 & & \\
\hline & Ath & M & $\mathrm{J}-\mathrm{S}$ & Yes & Both & Since Mar 2008 & & \\
\hline & Myk & M & $\mathrm{J}-\mathrm{S}$ & Yes & Both & Since Mar 2008 & & \\
\hline & Mil & M & $\mathrm{J}$ & Yes & Mother & Since Mar 2010 & & \\
\hline & Kor & M & $\mathrm{J}$ & Yes & Mother & Since Mar 2009 & & \\
\hline & Vid & M & $\mathrm{J}$ & Yes & Mother & Since Mar 2009 & & \\
\hline \multirow[t]{17}{*}{ B } & Pap & $\mathrm{F}$ & A & Yes & Both & Until Jan 2010 & Rainy season: & Rainy season: \\
\hline & Sip & $\mathrm{F}$ & A & Yes & Both & Whole study period & AK: 25.7 & Mean: 2595 (483) \\
\hline & Alo & M & A & No & Unknown & Until Sept 2009 & FK: 24.8 & Min: 649 \\
\hline & Gig & M & $\mathrm{A}$ & No & Unknown & Since May 2008 & MCP: 49.0 & Max: 3406 \\
\hline & Min & M & A & Yes & Both & Until July 2008 & & \\
\hline & Nar & M & A & Yes & Both & Until June 2008 & Dry season: & Dry season: \\
\hline & Neg & M & A & No & Unknown & Since Apr 2009 & AK: 26.1 & Mean: 2042 (473) \\
\hline & Obi & M & A & No & Unknown & Until May 2008 & FK: 23.9 & Min: 636 \\
\hline & Pan & M & A & No & Unknown & Since Apr 2009 & MCP: 54.9 & Max: 3661 \\
\hline & Rot & M & A & No & Unknown & Since Apr 2009 & & \\
\hline & Bor & $\mathrm{F}$ & S-A & Yes & Both & Whole study period & & \\
\hline & $\mathrm{Sab}$ & $\mathrm{F}$ & S-A & Yes & Both & Until Jan 2010 & & \\
\hline & For & $\mathrm{F}$ & $\mathrm{J}-\mathrm{S}$ & Yes & Both & Whole study period & & \\
\hline & Jol & M & $\mathrm{J}$ & Yes & Mother & Since Mar 2010 & & \\
\hline & $\mathrm{Lab}$ & M & $\mathrm{J}$ & Yes & Mother & Since Mar 2009 & & \\
\hline & Rut & M & $\mathrm{J}-\mathrm{S}$ & Yes & Both & Whole study period & & \\
\hline & Saw & M & $\mathrm{J}$ & Yes & Mother & Since Mar 2009 & & \\
\hline \multirow[t]{8}{*}{$\mathrm{F}$} & Dom & $\mathrm{F}$ & A & Yes & Mother & Whole study period & Rainy season: & Rainy season: \\
\hline & Jam & $\mathrm{F}$ & A & Yes & Mother & Until May 2008 & AK: 16.4 & Mean: 2141 (571) \\
\hline & Luc & $\mathrm{F}$ & A & Yes & Both & Whole study period & FK: 15.4 & Min: 158 \\
\hline & But & M & A & No & Unknown & Whole study period & MCP: 78.4 & Max: 3508 \\
\hline & Gus & M & A & No & Unknown & Since Sept 2008 & & \\
\hline & Lao & M & A & No & Unknown & Until Dec 2009 & Dry season: & Dry season: \\
\hline & Ori & M & A & No & Unknown & Whole study period & AK: 25.8 & Mean: 1946 (515) \\
\hline & Ang & $\mathrm{F}$ & $\mathrm{J}$ & Yes & Mother & Since Mar 2010 & FK: 24.1 & Min: 372 \\
\hline
\end{tabular}


Table I (continued)

\begin{tabular}{|c|c|c|c|c|c|c|c|c|}
\hline Group & ID & Sex & $\begin{array}{l}\text { Age } \\
\text { class }\end{array}$ & $\begin{array}{l}\text { Natal to } \\
\text { group? }\end{array}$ & $\begin{array}{l}\text { Parents } \\
\text { known? }\end{array}$ & $\begin{array}{l}\text { Time in } \\
\text { group }^{\mathrm{a}}\end{array}$ & $\begin{array}{l}\text { Home range size } \\
(\mathrm{AK} / \mathrm{FK} / \mathrm{MCP}) \\
{[\mathrm{ha}]^{\mathrm{b}}}\end{array}$ & $\begin{array}{l}\text { Mean }( \pm \mathrm{SD}) \text {, } \\
\text { min and max } \\
\text { daily path } \\
\text { length }[\mathrm{m}]^{\mathrm{b}}\end{array}$ \\
\hline \multirow{15}{*}{$\mathrm{J}$} & Aru & $\mathrm{F}$ & $\mathrm{J}$ & Yes & Both & Apr-May 2008 & MCP: 94.7 & Max: 4260 \\
\hline & Gue & $\mathrm{F}$ & $\mathrm{J}$ & Yes & Mother & Since Mar 2010 & & \\
\hline & Mon & $\mathrm{F}$ & $\mathrm{J}-\mathrm{S}$ & Yes & Both & Whole study period & & \\
\hline & Cas & $\mathrm{M}$ & $\mathrm{J}$ & Yes & Mother & Since Apr 2009 & & \\
\hline & $\mathrm{Nev}$ & M & $\mathrm{J}-\mathrm{S}$ & Yes & Both & Whole study period & & \\
\hline & Tri & $\mathrm{M}$ & $\mathrm{J}$ & Yes & Mother & Since Apr 2009 & & \\
\hline & Bur & $\mathrm{F}$ & A & Yes & Both & Until Feb 2010 & Rainy season: & Rainy season: \\
\hline & Cam & $\mathrm{F}$ & A & Yes & Both & Whole study period & AK: 36.6 & Mean: 2053 (592) \\
\hline & Bor & M & A & No & Unknown & Whole study period & FK: 30.8 & Min: 585 \\
\hline & Kas & M & A & No & Unknown & Whole study period & MCP: 193.9 & Max: 3960 \\
\hline & Usb & M & S-A & Yes & Both & Whole study period & & \\
\hline & $\mathrm{Col}$ & $\mathrm{F}$ & $\mathrm{J}$ & Yes & Mother & Since Mar 2010 & Dry season: & Dry season: \\
\hline & Geo & $\mathrm{F}$ & $\mathrm{J}$ & Yes & Mother & Since Mar 2009 & AK: 19.1 & Mean: 1943 (354) \\
\hline & Mal & $\mathrm{F}$ & $\mathrm{J}-\mathrm{S}$ & Yes & Both & Whole study period & FK: 18.9 & Min: 527 \\
\hline & Bru & M & $\mathrm{J}-\mathrm{S}$ & Yes & Both & Whole study period & MCP: 91.1 & Max: 3226 \\
\hline
\end{tabular}

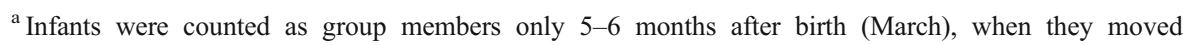
independently from their mothers and were individually marked with unique nylon collars

${ }^{\mathrm{b}}$ We did not collect data for group B in February 2009 because of battery problems with the GPS collar and group J from July to August 2009 because we were not able to capture an adult male

$I D$ animal identity (radio-collared males in bold); $F$ female; $M$ male; $A$ adult $(>2.5$ yr); $S$ subadult (1-2.5 yr); $J$ juvenile ( $<1 \mathrm{yr})$; $A K$ adaptive kernel (90\%); $F K$ fixed kernel (90\%); $M C P$ minimum convex polygon (100\%); Min minimum; Max maximum; $\mathrm{SD}=$ standard deviation. Rainy season $=$ NovemberMarch; dry season $=$ April-October

\section{Data Collection}

We continuously observed 4 groups of red-fronted lemurs (A: 8-13 individuals; B: 9-12 individuals; F: 9-11 individuals; J: 7-9 individuals) between March 2008 and March 2010 covering all ecological and reproductive seasons (total observation time: $\mathrm{A}=484 \mathrm{~h} ; \mathrm{B}=617 \mathrm{~h} ; \mathrm{F}=361 \mathrm{~h} ; \mathrm{J}=436 \mathrm{~h}$; all groups=1898 h). For details on group composition and group changes see Table I. We conducted observations between $c a$. 07:00-10:00 $\mathrm{h}$ and 14:00-17:00 $\mathrm{h}$ each day. We observed each group every second day, alternating between the morning and the afternoon.

When the group was stationary, we conducted group scans (Altmann 1974) every $15 \mathrm{~min}$ ( $\mathrm{ca} .7600$ scans in total) to note 1) the proportion of group members (in \%) within a $10-\mathrm{m}$ radius around the oldest female-which usually has the best sociogenetic connectivity in the group (Etz 2010)-and 2) whether all group members could be detected within a $20-\mathrm{m}$ radius or not. We randomly selected 80 scans (ca. $1 \%$ of the total scan number) from different groups for the rainy (November-March) and the dry (April-October) seasons for further analyses. Because these results were a prerequisite for the calculation of followership, we present them here. The proportion of group members within a $10-\mathrm{m}$ radius around 
the oldest female of the group was slightly higher in the dry $(n=80 ; 58.1 \pm 33.5 \%)$ vs. the rainy $(n=80 ; 57.1 \pm 34.7)$ season but the difference was not significant (MannWhitney $U$ test: $U=3170.5, z=-0.1, p=0.92$ ). There was no difference in the proportion of scans in which we detected all group members within a $20-\mathrm{m}$ radius between the dry $(n=80 ; 90.0 \%)$ and the rainy $(n=80 ; 87.5 \%$; binary logistic regression, code: $1=$ all individuals detected; $0=$ not all individuals detected: $F=0.25$, $p=0.62$ ) seasons, either. Given the high degree of group cohesion throughout the year suggested by these results and because red-fronted lemurs constantly produce contact calls while foraging or locomoting (Pereira and Kappeler 1997; Pflüger and Fichtel unpubl. data), we assumed individuals of our focal groups to be in permanent visual or acoustic contact with each other.

When a group was on the move, we used a previously established operational definition to identify the initiation and termination of a group movement as well as followers and overtaking events. It has been argued that definitions of group movements should account for a number of taxon-specific characteristics, e.g., different traveling types (directed movements vs. "feed-as-you-go," amoeboid-like movements that do not necessarily require an initiator or coordination among group members, e.g., bonobos, Pan paniscus: Wrangham 2000), mean travel distances, latencies between movements, and distances between group members (Pyritz et al. 2011). Therefore, we defined group movements based on empirical data from the same groups collected during a pilot study (Pyritz et al. 2010): We observed all group members as focal individuals for $2 \mathrm{~h}$ and recorded any movement of $>3$ body lengths that occurred during this time, specifying the total distance covered, the spatial distance to the next neighbor after the end of the movement, and the latency between 2 subsequent movements. Based on meaningful breaks in the frequency distributions of these data, we defined a group movement as follows: An individual (the initiator) that was stationary for $\geq 4 \mathrm{~min}$ moved $\geq 15 \mathrm{~m}$ away from its group members in a directed manner without pausing. Other group members were termed followers if their movement diverged $\leq 45^{\circ}$ from the trajectory of the movement of the initiator and if they arrived within a 6-m radius around the terminator $\leq 10 \mathrm{~min}$ after termination of the movement. That means our definition of followers refers to recruitment success of the initiator measured according to a time and distance threshold. Overtaking occurred if a follower outdistanced the leader, i.e., the individual at the forefront of the group, by $>3$ body lengths without diverging $>c a .45^{\circ}$ of the initial trajectory of travel. Further, we estimated the distance the group traveled in each movement with the help of the grid cells (Fig. 1) that were additionally subdivided into quarters. A movement was considered as terminated when the leading individual was again stationary for $\geq 4 \mathrm{~min}$. We did not take into account movements associated with conflict or sexual consort. Because of this definition, we treated all group movements as independent events for statistical purposes.

We used data on all departure attempts to analyze initiatorship, including movements that we could not follow until termination. We conducted all further analyses using only data of completely observed group movements, including number and identity of followers, identity of terminator, potential overtaking events, and distances traveled. As in other studies (Jacobs et al. 2008; Sueur and Petit 2008a; Trillmich et al. 2004), we recorded a successful group movement if the initiator enlisted $\geq 1$ follower. For calculations on overtaking events and distances of group movements, we did not take unsuccessful attempts, i.e., movements without 
followers, into account. However, we used them in the analyses of followership because unsuccessful initiations yield information on the social connectivity of initiating individuals (Sueur and Petit 2008a,b). Because the sample size for overtaking events with a subadult initiator was $n=1$, we could not calculate any statistics regarding possible age effects. Because the sizes of our focal groups were small and the scans suggested that group cohesion was permanently high, we assumed that each individual had the opportunity to follow each group movement and not only the individuals in a certain radius around the initiator at departure (Jacobs et al. 2011). Therefore, we measured recruitment success as the proportion of all group members (in \%) following the initiator, corrected for fluctuations of individual group size over time (Table I).

L. W. Pyritz and Malagasy field assistant J.-P. Tolojanahary collected behavioral data together from March-May and September-December 2008, June-August 2009, and January-March 2010. J.-P. Tolojanahary continued data collection on his own in the meantimes from June-August 2008, January-May and September-December 2009. One observer conducted group scans while groups were stationary. As soon as the group started moving, 1 observer followed the initiator of a group movement and collected data according to the protocol introduced in the preceding text. If a second observer was present, he collected data on distances between the initiator and followers and latencies of followers at departure. These data are not included in this paper but are currently being analyzed for a separate publication on the effects of affiliation and relatedness on follower behavior.

We collected data on ranging behavior of the groups throughout the study period by fitting 1 adult male per group with a custom-made GPS-RF tag (Kümmeth and Heidrich 2007) in March-June 2008, September-November 2008, December 2008-May 2009, and June-September 2009. Because group cohesion was permanently high, we assumed the movements of 1 group member provided a realistic proxy of the movement patterns of the entire group. The tags logged spatial position of the subjects every 30 min continuously for 2-4 mo. We equipped subjects with GPS collars during brief anesthesia (induced by applying $0.2 \mathrm{ml}$ of GMII; Rensing 1999), after blow-pipe darting by an experienced Malagasy technician. Anaesthetised individuals recovered within $2 \mathrm{~h}$ and were returned to their social groups. We analyzed the 12-mo GPS data according to season (rainy: November-March; dry: April-October). We calculated daily path lengths for each group by adding the distances calculated between subsequent GPS coordinates for each day and seasonal home range estimates with minimum convex polygon (MCP 100\%), as well as with adaptive and fixed kernel (AK 90\%, FK 90\%) methods to provide a measure of data variability (Boyle et al. 2009; Table I). We did not exclude any data points because the impact of autocorrelation on home range estimates has been rated as moderate or negligible, especially for large sample sizes (Blundell et al. 2001; Swihart and Slade 1997). We conducted spatial computations via Home Range Extension (Rodgers and Carr 2002) for ArcView GIS 3.3 (Environmental System Research Institute, Redlands, California).

\section{Statistical Analyses}

To analyze potential effects of sex, age, and seasonality on initiatorship, overtaking events, followership, and traveled distances, we calculated a $\chi^{2}$-test, 2 generalized 
linear mixed effects models (GLMM), and 2 linear mixed effects models (LMM; Faraway 2005; Zuur et al. 2009). For details regarding response variables and fixed and random factors of the models see Table II. Models were fitted using R (R Development Core Team, Vienna, Austria, 2010) with the lme4- and languageRpackages. We used Akaike's Information Criterion (Akaike 1974) to remove parameters stepwise (factors were excluded if this improved the model fit by $>2$ AIC units) and select the most parsimonious model with the best fit to the data (Bolker et al. 2008; Johnson and Omland 2004). We used maximum likelihood ratio tests to test whether a fixed factor explained a significant amount of the variance and to test the final model with fixed factors against the null model including only the random factors (Faraway 2006). For the LMM, For the LMM, R does not display $p$-values for single fixed factors in the model summary. We used Markov chain Monte Carlo methods to generate $p$-values for these parameters instead (Bates and Sarkar 2007). We used a Mann-Whitney $U$ (MWU) test to compare daily travel paths between different ecological seasons. The significance level was set at $\alpha=0.05$ for all tests. To be able to present the results of the binomial GLMM on initiations graphically, we calculated mean individual initiation rates per hour for each month (Fig. 2).

\section{Results}

\section{General Ranging Patterns}

GPS tracking revealed that daily path length of a group ranged from $158 \mathrm{~m}$ to $4260 \mathrm{~m}(n=1107)$ with an overall mean $( \pm$ standard deviation $)$ of $2047( \pm 129) \mathrm{m}$. Mean daily path length during the rainy season $(2196 \pm 272 \mathrm{~m} ; n=238)$ was significantly longer than during the dry season $(1968 \pm 49 \mathrm{~m} ; n=869$; MWU test: $U=$ $78891.0, z=-5.5, p<0.001)$. Home range size varied only slightly between ecological seasons for groups A and B but varied considerably between ecological seasons for groups $\mathrm{F}$ and J. Numerical estimates varied widely depending on the particular estimator used (Table I). Whereas kernel estimates (AK and FK combined) ranged from a minimum of 15.4 ha to a maximum of 36.6 ha, with a mean of $22.3 \pm 4.8$ ha, MCP estimates ranged between 49.0 ha and 193.9 ha with a mean of $84.4 \pm 47.6$ ha.

Initiatorship

We observed a total of 721 initiation attempts by adults (564 females; 139 males) and subadults ( 6 females; 12 males). The interaction between reproductive season and sex was not part of the model with the best fit (Table II). The final binomial GLMM with single initiation events as dependent variable ("yes" for the initiator; "no" for every other group member for each group movement to control for sex- and aged-biased group composition and fluctuations over time) contained sex, age, and the interaction between ecological season and sex as fixed factors and subject identity nested in group as random factor and performed significantly better than the null model $\left(n=721\right.$; GLMM: $\left.\chi^{2}=168.3, \mathrm{df}=4, p<0.001\right)$. However, only sex and age were significant components of the model (Table II), revealing that adult females led group movements most often independent of reproductive and ecological season. We 


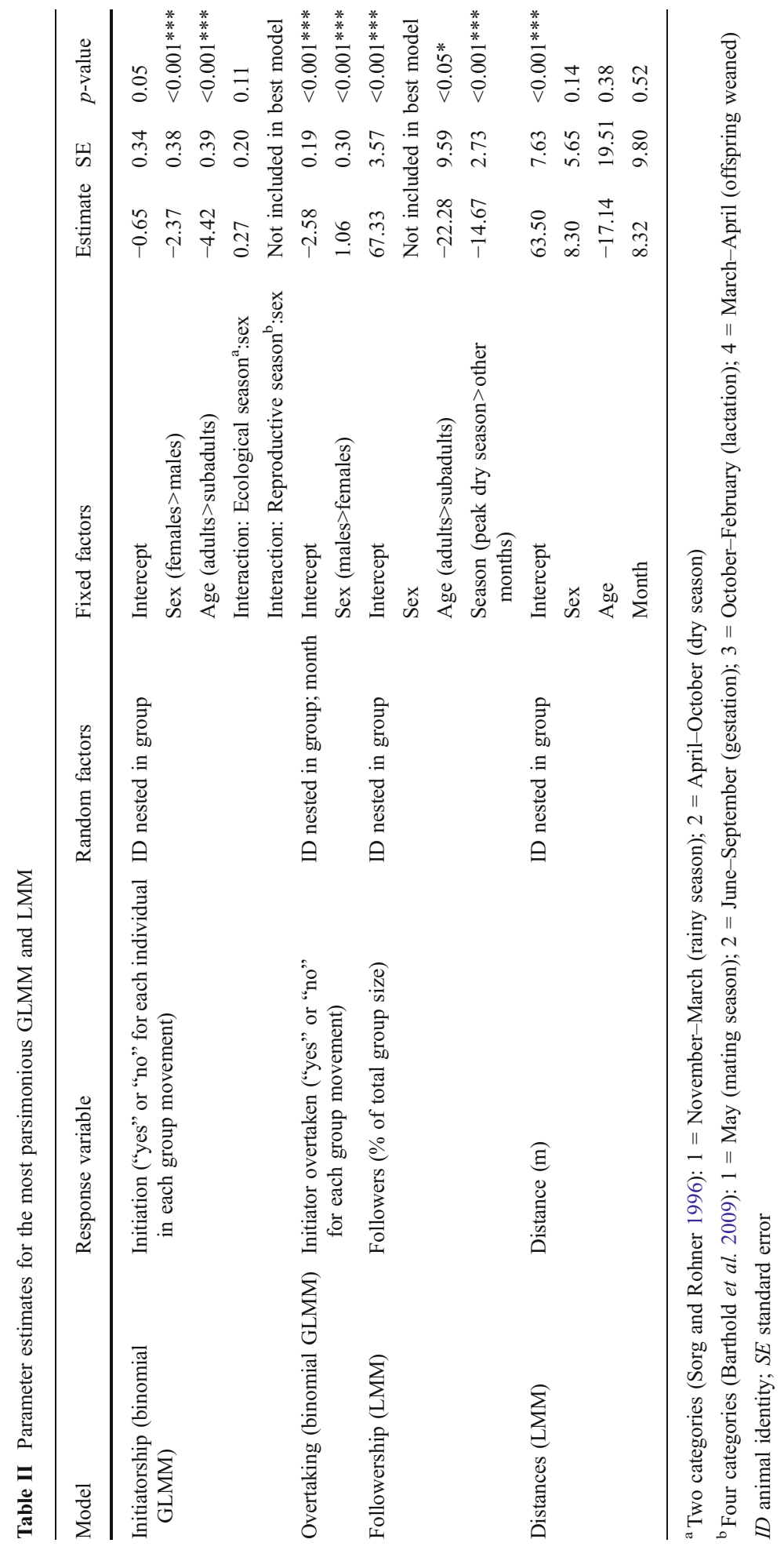




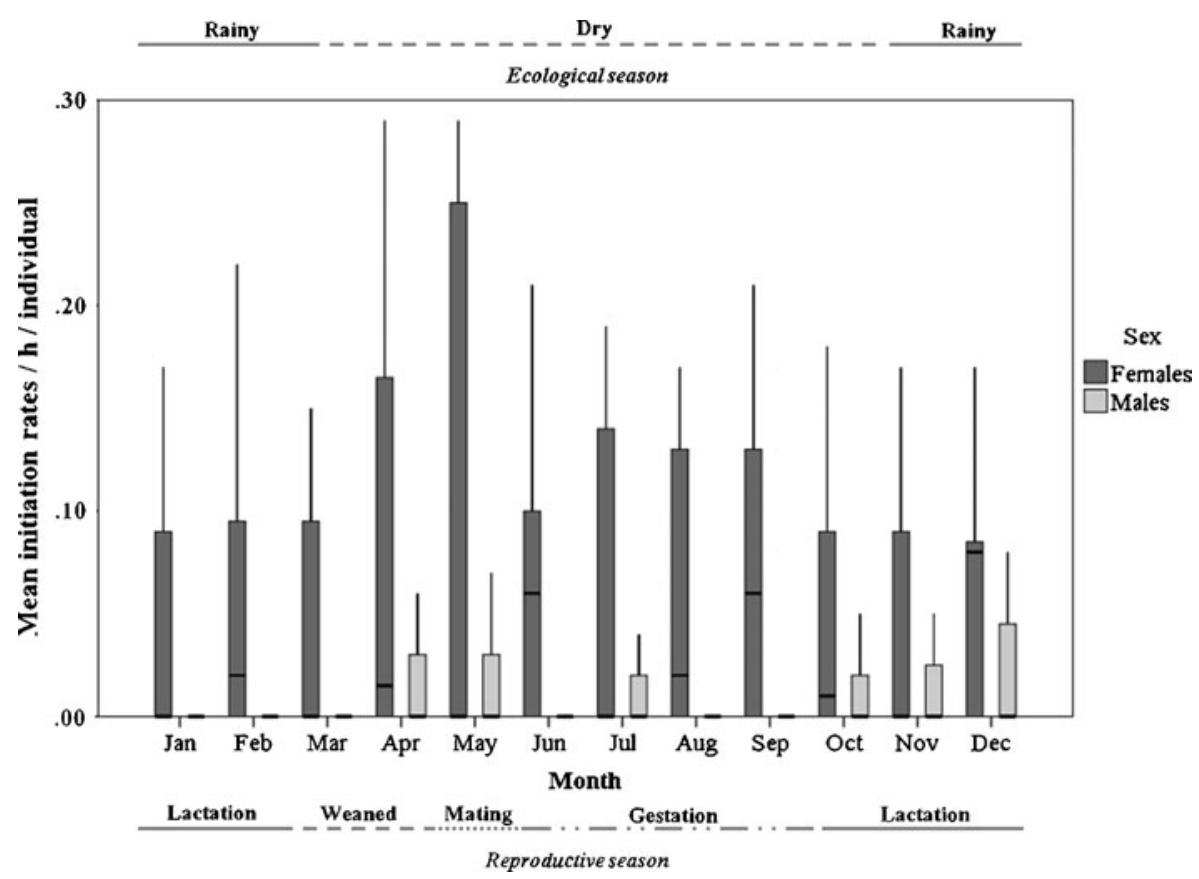

Fig. 2 Mean initiation rates per hour per individual in relation to sex throughout the annual cycle, i.e., different ecological and reproductive seasons (ecological seasons: rainy = November-March; dry = AprilOctober; reproductive seasons: mating = May; gestation $=$ June-September; lactation = October-February; offspring weaned $=$ March-April). Shown are medians, 25-75\% quartiles (box), and ranges (whiskers). We removed outliers. Shown are combined data of the 4 focal groups.

conducted further analyses using only data from completely observed group movements $(A=202 ; B=251 ; \mathrm{F}=106 ; \mathrm{J}=141$; total=700), of which $660(94.3 \%)$ were successful, i.e., enlisted $\geq 1$ follower. There was no difference concerning sex of unsuccessful initiators ( 21 females; 19 males; $\chi^{2}$-test: $\chi^{2}=0, \mathrm{df}=1, p=1$ ), and unsuccessful attempts occurred year-round in both sexes without seasonal patterns.

\section{Overtaking}

In general, overtaking events were relatively rare $(n=62)$; i.e., they occurred during only $9.4 \%$ of 660 successful movements. Hence, the initiator of a group movement was also the terminator in most cases. The model including sex as fixed factor and month and individual identity nested within group as random factors explained significantly more variance regarding overtaking events than the null model $(n=660$; GLMM: $\left.\chi^{2}=8.38, \mathrm{df}=1, p<0.01\right)$ : Male initiators were overtaken more often than female initiators (females: 7.0\%; males: 20.2\%; Fig. 3; Table II). Overtaking occurred without aggression in $100 \%$ of observed cases.

\section{Followership}

On average, adults were followed by a higher percentage of group members $(n=691$; $55.8 \pm 29.8 \%)$ than subadults $(n=9 ; 31.7 \pm 21.5 \%)$ when leading a group movement 
Fig. 3 Proportion of overtaking events in relation to sex of the initiator. Shown are percents of group movements. $N_{\text {movements }}$ (total $/$ overtaken) $=541 / 38$ for females; $N_{\text {movements }}$

(total/overtaken) $=119 / 24$ for males. Note that the ordinate starts at $50 \%$. Shown are combined data of the 4 focal groups.

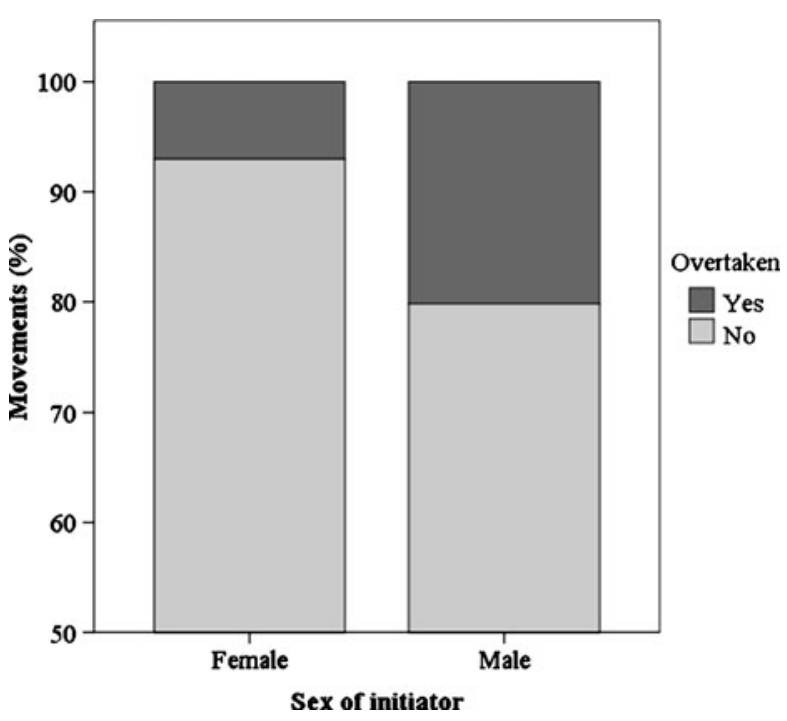

(Fig. 4). Further, initiators had more followers during the peak dry season between September and November $(n=207 ; 67.0 \pm 31.7 \%)$ vs. other months/seasons $(n=493$; $50.7 \pm 27.7 \%$; Fig. 5). In contrast, sex had no effect on the number of recruited group members and was not included in the model with the best fit (females: $n=562 ; 55.6 \pm$ $28.8 \%$ followers; males: $n=138 ; 55.1 \pm 33.7 \%$ followers). The final model performed significantly better than the null model $\left(n=700\right.$ LMM: $\chi^{2}=44.9, \mathrm{df}=3, p<0.001$; Table II).

\section{Distances of Single Group Movements}

Distances of single group movements ranged from $15 \mathrm{~m}$ to $580 \mathrm{~m}$, with a median of $60.0 \mathrm{~m}$. Neither sex nor age of the initiator affected distances covered in a single

Fig. 4 Percent followers during group movements in relation to age class of the initiator. Shown are medians, $25-75 \%$ quartiles (box), and ranges (whiskers). $N=691$ for adults; $N=9$ for subadults. Shown are combined data of the 4 focal groups. $* p<0.05$.

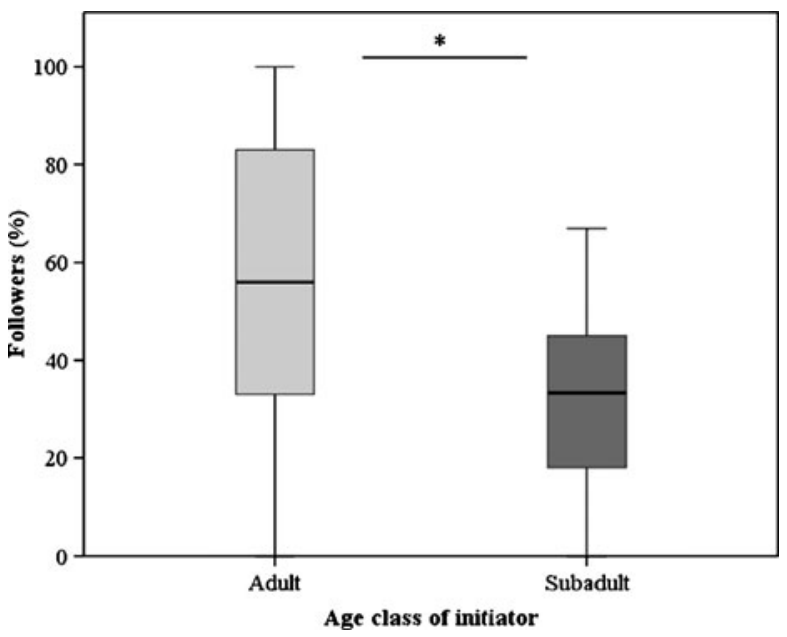


Fig. 5 Percent followers during group movements in relation to ecological season. Shown are medians, $25-75 \%$ quartiles (box), and ranges (whiskers). $N=299$ for (transition to) the dry season (April-August); $N=207$ for the peak dry season (September-November); $N=194$ for (transition to) the rainy season (December-March). Shown are combined data of the 4 focal groups. $* * * p<0.001$.

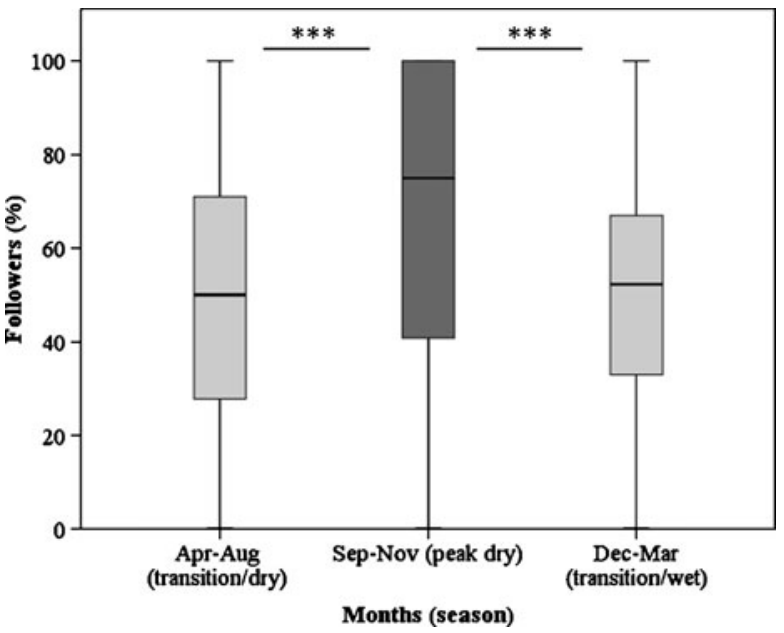

movement, i.e., group movements that were led by a female $(n=562 ; 71.2 \pm 53.1 \mathrm{~m})$ or adult $(n=691 ; 72.8 \pm 54.5 \mathrm{~m})$ did not cover significantly larger distances than those led by males $(n=138 ; 77.8 \pm 58.8 \mathrm{~m})$ or subadults $(n=9 ; 55.0 \pm 28.5 \mathrm{~m})$. Further, distances of observed group movements did not vary significantly among months. Accordingly, the respective model did not perform better than the null model ( $n=660$ LMM: $\chi^{2}=15.0, \mathrm{df}=13, p=0.31$; Table II).

\section{Discussion}

We analyzed ranging patterns and processes of group movements in free-ranging red-fronted lemurs throughout different seasons. Mean daily path length was longer during the rainy than the dry season. Home range size estimates varied strongly in 2 groups depending on season (F, J) and estimator (all groups). Females and males of different age classes successfully initiated group movements but adult females did so most often, irrespective of ecological and reproductive season. However, female initiators did not enlist more followers than males. Adult individuals had higher recruitment success. Further, recruitment success was higher at the peak of the dry season vs. other months. Neither sex nor age of the initiator nor season affected distances of single movements.

\section{General Ranging Patterns}

Home Range Use Throughout Different Seasons Home range size did not differ extensively across seasons in groups A and B, which might be due to the fact that their home ranges are close to the river, so that daily excursions to water holes were not necessary. In contrast, home range estimates differed considerably with season in groups $\mathrm{F}$ and $\mathrm{J}$ (Table I). In group $\mathrm{F}$, this difference might be due to daily excursions to water holes during the dry season because their home range is farthest away from the Kirindy River (Scholz and Kappeler 2004). Further, group F conducted 
migrations out of the regular home range on February 7 and March 17, 2009. Group J conducted a similar migration to a far-off area between March 16 and 28, 2009 (Kappeler 2000). Unfortunately, we were not able to observe these migrations directly. However, subsequent surveys suggested that they lead to patches of preferred feeding trees of the lemurs with short flowering or fruiting intervals between January and March, including Astrocassine pleurostyloides, Strychnos decussate, and Berchemia discolour (Sorg and Rohner 1996).

Overdorff (1993) reported similar observations of migrations to remote resources of red-fronted lemurs in Ranomafana, which left their usual home range during a time of low fruit availability to feed in a plantation of Chinese guava (Psidium cattleyanum). Pronounced seasonal home range changes based on detailed ranging data have been described for many anthropoid species as well, e.g., red colobuses (Colobus badius tephrosceles: Clutton-Brock 1975), chacma baboons (Anderson 1981), Sichuan snub-nosed monkeys (Rhinopithecus roxellana: Li et al. 2000), and white-faced capuchins (Baker 2001). However, none of these studies has looked at the effects of seasonality on coordination processes at the same time so that a comparative discussion of our findings in this context is currently not possible.

Daily Path Length Daily path length increases during the dry season owing to longer foraging movements in chacma baboons (Anderson 1981), vervets (Cercopithecus aethiops: Struhsaker 1967), and Verreaux's sifakas (Richard 1978). However, and in contrast to our prediction, the mean daily path length combining data for all groups was larger in the rainy season than in the dry season. This is presumably due to longer daily travel paths of groups $\mathrm{F}$ and $\mathrm{J}$ during their migrations in February and March. Thus, it may be that at least some groups of red-fronted lemurs at Kirindy respond to ecological constraints by reducing activity to save energy, but this is obscured by other factors.

\section{Coordination of Group Movements}

Initiation, Overtaking, and Termination Supporting our prediction, group members of all sex and age classes initiated group movements across the year. However, adult females did so most often, irrespective of ecological and reproductive season and related seasonal variation in home range use. Overtaking occurred rarely, and female initiators were overtaken less often than male initiators. Hence, females that initiated a group movement also terminated it in almost all cases, suggesting that females have a strong influence on other group members regarding decisions on when and where to move and where to stop. Interestingly, if overtaking events occurred, they were never accompanied by aggressive behavior. This could mean that the decisions about where to go do not create conflicts that need to be resolved aggressively. However, termination of a group movement might already be predetermined by a goal-directed departure (Sueur et al. 2010) or be based on a second consensus decision, so that overtaking events do not necessarily imply that the decision where to stop will be made by the overtaking individual (Pyritz et al. 2011). In fact, aggressive behavior during decision-making processes has so far not been reported in any species, indicating that decisions about when and where to go might be based on consensus decisions at departure or destination (Conradt and Roper 2007). 
Leadership in Free-ranging and Captive Groups In line with our prediction, redfronted lemurs displayed distributed but highly skewed and stable leadership of adult females, which agrees with the results of a previous study on red-fronted lemurs in a rain forest habitat (Erhart and Overdorff 1999). Interestingly, however, a study on a captive group of brown lemurs did not reveal any effect of sex or age on coordination of group movements (Jacobs et al. 2008). This group was housed in a 0.2-ha enclosure and experienced neither predation risk nor seasonal resource variation, which may promote less skewed and more equally shared leadership. This suggests that comparative studies in captivity and in the wild can reveal important insights about factors explaining why certain individuals exert more social influence.

Female Leadership and Physiological Demands of Reproduction Female leadership has been discussed as a nonaggressive strategy to enhance individual foraging efficiency and nutritional intake to compensate added energetic costs of gestation and lactation in a number of anthropoid and lemur species: squirrel monkeys (Saimiri oerstedi: Boinski 1988, 1991), diademed sifakas (Propithecus diadema edwardsi) and red-fronted lemurs (Erhart and Overdorff 1999), and Verreaux's sifakas (Trillmich et al. 2004). However, reproduction in red-fronted lemurs is seasonal, i.e., mating, gestation, and lactation occur between May and February (Barthold et al. 2009). Nevertheless, female leadership occurred year-round without significant differences among months.

Energetic costs of reproduction accrue primarily through lactation and infant carrying (Oftedal 1985; Pond 1977; Tarnaud 2006). Thus, females may continue initiating and leading group movements between the weaning of an infant and the next mating season (February-May) to compensate for the physiological depletion of the past months or to store fat in advance of the next gestation period, as suggested for ringtailed lemurs (Pereira 1993). However, lactating brown lemurs increased their food intake only during the early lactation period (first $3 \mathrm{mo}$ ) when the frequency of suckling is highest and infants do not yet consume solid food items independently (Tarnaud 2006). Thus, quantitative energetic demands seem to decrease over the course of the lactation period of Eulemur, making compensatory postweaning leadership of females less likely.

Other studies revealed a strong impact of nutritional provisioning on reproduction in lemurs, i.e., females tended to give birth to twins instead of a single infant when resources were plentiful (ringtailed lemurs: Nunn and Pereira 2000). Thus, detailed data on nutritional intake and quality of consumed food items are required for a better understanding of female energetic demands. For instance, females may lead the group to resources providing them with specific micronutrients they lack after lactation during the migrations at the beginning of the rainy season, which coincide with the end of the weaning process. Future studies exploring this sex difference in more detail would ideally also include analyses of sex differences in metabolic rate (Simmen et al. 2010) or motivation to exploit specific resources (King et al. 2009).

Female Leadership and Philopatry An alternative explanation for year-round female leadership might be the fact that females are the predominantly philopatric sex in red-fronted lemurs. Philopatry may involve better knowledge of the home range and more experience regarding (seasonal) resource distribution, e.g., long-tailed 
macaques (Macaca fascicularis: van Noordwijk and van Schaik 1987) and gorillas (Watts 1994). In particular, this may account for the extraordinary movements during the rainy season to scattered, ephemeral resources. However, females are also the philopatric sex in chacma baboons, but males initiate and lead more group movements in this species, although the sex-specific difference regarding initiatorship is not as pronounced as in red-fronted lemurs (Stueckle and Zinner 2008). Therefore, characteristics of the social structure, such as male dominance in chacma baboons (Bulger 1993), might have a greater effect on coordination and leadership than residence patterns. Clearly, more studies on species with additional combinations of residence and dominance patterns are required to disentangle these factors.

The findings regarding the distances of single group movements also do not support the philopatry hypothesis as a reason for female leadership: Sex and age class of the initiator did not influence distances of single group movements, and month had no effect either. In addition, the mean distance of movements was short (ca. $70 \mathrm{~m})$. Hence, there seems to be a rather small-scale distribution pattern of feeding and resting sites in the home range throughout the year that does not require long movements between scattered resources by particularly well informed individuals.

Social Structure, Recruitment Success, and Expected Decision Type Philopatric female red-fronted lemurs are usually closely related to several other members of their group, e.g., sisters or their offspring from previous years, and are well connected in affiliative social networks, whereas males switch groups more often (Ostner and Kappeler 2004; Wimmer and Kappeler 2002). Researchers have proposed that group members with strong sociogenetic network relations will be followed more often or more rapidly when initiating a movement, and thus be more likely to act as leaders (King et al. 2009; King and Sueur 2011). In fact, King et al. (2008) found that close social ties to the male leader mediated consensus costs of follower behavior in chacma baboons traveling to experimental food patches. Further, Jacobs et al. (2011) showed that affiliative network relations among individuals were the best predictor regarding joining of group movements in a captive group of brown lemurs, i.e., an individual's decision to join a movement depended on the decision taken by its preferred social partners.

Females might have been followed faster by more individuals at departure, which could provide positive social feedback for female initiators (these data are currently tested). However, females were not more successful in recruiting a larger number of followers than males. Hence, network relations do not seem to be the only determinant of recruitment success. In contrast, in Verreaux's sifakas, which also display female philopatry (Brockman 1999; Kappeler and Fichtel 2011) and predominantly female leadership, female initiators had a higher recruitment success than males (same operational definition of followership as in this study: Trillmich et al. 2004). This might be related to different dominance patterns: Adult female sifakas are socially dominant over males (Richard 1987) but female red-fronted lemurs are not (Pereira et al. 1990). Hence, social dominance of females seems to have a strong influence on the joining behavior of conspecifics. The lack of social hierarchy in our focal species could also explain the relatively high proportion of group movements successfully led by males (Erhart and Overdorff 1999) vs. other 
primate species with pronounced female dominance: squirrel monkeys (Boinski 1991), ringtailed lemurs (Sauther and Sussman 1993), diademed sifakas (Erhart and Overdorff 1999); cf. Verreaux's sifakas (Trillmich et al. 2004).

The joining behavior of group members, i.e., the decision making process on the individual level, can also be linked to social relationships among individuals. For instance, an egalitarian social structure characterized by tolerant relations among group members coincided with equally shared decision making involving a voting process (quorum) in Tonkean macaques (Macaca tonkeana) whereas rhesus macaques (Macaca mulatta), with their more pronounced dominance hierarchy, exhibited only partially shared consensus decisions (Sueur and Petit 2008a,b; Sueur et al. 2010). Further, Jacobs et al. (2011) showed that joining behavior in brown lemurs depended on previous actions of the preferred social partner, i.e., the decision was not made by a single leader but rather self-organized, with each individual being able to influence the decision outcome. Given the egalitarian social structure of our focal species, we would also expect shared consensus decision making in red-fronted lemurs during departure, i.e., the actions of several group members should contribute to the decision outcome.

Age, Ecological Seasonality, and Recruitment Success In many primates, adult and, thus, supposedly more knowledgeable and experienced group members initiate and lead group movements more often than subadults: Japanese macaques (Macaca fuscata: Itani 1963), chimpanzees (Pan troglodytes: Boesch 1991), squirrel monkeys (Boinski 1991), gorillas (Stewart and Harcourt 1994), and white-faced capuchins (Boinski and Campbell 1995). We also observed mostly adult individuals initiating and leading group movements in red-fronted lemurs. Further, recruitment success seemed to be season dependent because the number of followers during the peak dry season was significantly higher than in the months before and after. This variability of group cohesion during movements between different seasons might be due to a number of reasons: Low resource abundance during the peak dry season may have resulted in more targeted movements of the whole group to single feeding trees and water holes vs. other months (Scholz and Kappeler 2004). Second, increased predation risk in the dry season should promote group cohesion. For instance, fossas prey more on lemurs during the dry season at Kirindy, when their main rainy season prey (tenrecs) are hibernating (Hawkins and Racey 2008). In fact, predation risk is thought to be generally higher when the habitat is more open due to defoliated trees (Janson and Goldsmith 1995). Finally, group cohesion might be higher due to increased intergroup competition for scarce resources during the dry season (Cheney 1992). However, the suggested difference in group cohesion is not reflected in the scan data presented in the Methods section. This may be because the groups were more cohesive only during traveling but not during stationary behavior. Further, the scan data are not directly comparable to the recruitment data because followers could arrive within close proximity to the terminator in a 10-min time window and did not have to stay there for a certain period. Finally, the resolution of the scan data $(\leq 10 \mathrm{~m})$ might be too low to detect seasonal differences in cohesion. Ideally, operational definitions of followership in future studies should take seasonal variation of group cohesion into account by assessing season-specific thresholds, e.g., individuals have to arrive within a 6-m radius around the terminator during the 
dry season but only within a $9 \mathrm{~m}$ radius in the rainy season to be termed followers (Pyritz et al. 2011).

\section{Conclusions}

Our results indicate variation in follower behavior in a free-ranging lemur species according to the age of the initiator and the ecological context. However, not all features varied with environmental conditions: Female leadership, which has been described for many anthropoid and lemur species, prevailed year-round, perhaps owing to special nutritional needs related to gestation and lactation. A comparison among other taxa suggested that social dominance patterns seem to influence follower behavior, i.e., this egalitarian species did not display sex-biased recruitment success, in contrast to despotic anthropoid and lemur taxa. Our results provide a comprehensive example of group coordination processes in lemurs that evolved group living independently of anthropoids. In the future, more studies of different primate taxa can build on these data to disentangle the effects of sex, age, dominance relations, and residence patterns and illuminate the evolutionary roots of coordination, leadership, and decision making in free-ranging primates.

Acknowledgments We acknowledge the authorization and support of this study by the Département de Biologie Animale, Université d'Antananarivo, the CAFF of the Direction des Eaux et Forêts, and the CNFEREF Morondava. For support and assistance in the field we thank Jean-Pierre Tolojanahary, Léonard Razafimanantsoa, Tianasoa Andrianjanahary, and the Equipe Kirindy. This manuscript benefited greatly from discussions with Dagmar Clough, Elise Huchard, Andrew King, Cornelia Kraus, and Cédric Sueur and comments by 2 anonymous reviewers. The German Research Foundation (DFG: KA 1082/16-1) and the German Academic Exchange Service (DAAD) kindly provided financial support. We also thank Joanna Setchell for her support during preparation of this special issue, and the International Journal of Primatology for funds that contributed toward the travel costs to the XXIIIth Congress of the International Primatological Society (IPS) in Japan.

Open Access This article is distributed under the terms of the Creative Commons Attribution Noncommercial License which permits any noncommercial use, distribution, and reproduction in any medium, provided the original author(s) and source are credited.

\section{References}

Akaike, H. (1974). A new look at the statistical model identification. IEEE Transactions on Automatic Control, 19, 716-723.

Altmann, J. (1974). Observational study of behavior: sampling methods. Behaviour, 49, 227-267.

Anderson, C. (1981). Subtrooping in a chacma baboon (Papio ursinus) population. Primates, 23, 445-458.

Baker, M. (2001). Variation in ranging patterns and habitat use by capuchin monkeys (Cebus capucinus) in a dry tropical forest. American Journal of Primatology, 54, 95.

Barthold, J., Fichtel, C., \& Kappeler, P. M. (2009). What is it going to be? Pattern and potential function of natal coat change in sexually dichromatic redfronted lemurs (Eulemur fulvus rufus). American Journal of Physical Anthropology, 138, 1-10.

Bates, D. M., \& Sarkar, D. (2007). lme4: Linear mixed-effects models using S4 classes. In R package version 0.9975-12, url http://CRAN.R-project.org/.

Bertram, B. C. R. (1978). Living in groups: Predators and prey. In J. R. Krebs \& J. B. Davies (Eds.), Behavioural ecology (pp. 64-96). Oxford: Blackwell. 
Blundell, G. M., Maier, J. A. K., \& Debevec, E. M. (2001). Linear home ranges: Effects of smoothing, sample size, and autocorrelation on kernel estimates. Ecological Monographs, 71, 469-489.

Boesch, C. (1991). The effects of leopard predation on grouping patterns in forest chimpanzees. Behaviour, 117, 220-242.

Boinski, S. (1988). Sex differences in the foraging behavior of squirrel monkeys in a seasonal habitat. Behavioral Ecology and Sociobiology, 23, 177-186.

Boinski, S. (1991). The coordination of spatial position: a field study of the vocal behaviour of adult female squirrel monkeys. Animal Behaviour, 41, 89-102.

Boinski, S. (1993). Vocal coordination of group movement among white-faced capuchin monkeys, Cebus capucinus. American Journal of Primatology, 30, 85-100.

Boinski, S., \& Campbell, A. F. (1995). Use of trill vocalisations to coordinate troop movement among white-faced capuchins: a second field test. Behaviour, 132, 875-901.

Bolker, B. M., Brooks, M. E., Clark, C. J., Geange, S. W., Poulsen, J. R., Stevens, M. H. H., et al. (2008). Generalized linear mixed models: a practical guide for ecology and evolution. Trends in Ecology and Evolution, 24, 127-135.

Bousquet, C. A. H., Sumpter, D. J. T., \& Manser, M. B. (2010). Moving calls: a vocal mechanism underlying quorum decisions in cohesive groups. Proceedings of the Royal Society B: Biological Sciences, 278, 1482-1488. doi:10.1098/rspb.2010.1739.

Boyle, S. A., Lourenço, W. C., da Silva, L. R., \& Smith, A. T. (2009). Home range estimates vary with sample size and method. Folia Primatologica, 80, 33-42.

Braune, P., Schmidt, S., \& Zimmermann, E. (2005). Spacing and group coordination in a nocturnal primate, the golden brown mouse lemur (Microcebus ravelobensis): the role of olfactory and acoustic signals. Behavioral Ecology and Sociobiology, 58, 587-596.

Brockman, D. K. (1999). Reproductive behaviour of female Propithecus verreauxi at Beza Mahafaly, Madagascar. International Journal of Primatology, 20, 375-398.

Brockman, D. K., \& van Schaik, C. P. (2004). Primate seasonality: Implications for human evolution. Cambridge: Cambridge University Press.

Bulger, J. B. (1993). Dominance rank and access to estrous females in male savanna baboons. Behaviour, $127,67-103$.

Chapman, C. A. (1990). Association patterns of spider monkeys: the influence of ecology and sex on social organization. Behavioral Ecology and Sociobiology, 26, 409-414.

Cheney, D. L. (1992). Intragroup cohesion and intergroup hostility: the relation between grooming distributions and intergroup competition among female primates. Behavioral Ecology, 3, 334-345.

Clutton-Brock, T. H. (1975). Ranging behavior of red colobus (Colobus badius tephrosceles) in the Gombe National Park. Folia Primatologica, 19, 368-379.

Conradt, L., \& Roper, T. J. (2003). Group decision-making in animals. Nature, 421, 155-158.

Conradt, L., \& Roper, T. J. (2005). Consensus decision making in animals. Trends in Ecology and Evolution, 20, 449-456.

Conradt, L., \& Roper, T. J. (2007). Democracy in animals: the evolution of shared group decisions. Proceedings of the Royal Society of London B: Biological Sciences, 274, 2317-2326.

Doran, D. (1997). Influence of seasonality on activity patterns, feeding behavior, ranging, and grouping patterns in Taï chimpanzees. International Journal of Primatology, 18, 183-206.

Erhart, E. M., \& Overdorff, D. J. (1999). Female coordination of group travel in wild Propithecus and Eulemur. International Journal of Primatology, 20, 927-941.

Etz, J. (2010). Social networks and communication in red-fronted lemurs. M.Sc. thesis, University of Göttingen.

Faraway, J. J. (2005). Linear models with R. London: Chapman \& Hall.

Faraway, J. J. (2006). Extending the linear model with R. London: Chapman \& Hall.

Fichtel, C., \& Hilgartner, R. (in press). Noises in the dark: Vocal communication in nocturnal pair-living primates. In J. Master, M. Gamba, \& F. Génin, (Eds.), Developments in primatology: Leaping ahead. Advances in Prosimian Biology. New York: Springer.

Fichtel, C., \& Kappeler, P. M. (2002). Anti-predator behaviour of group-living Malagasy primates: mixed evidence for a referential alarm call system. Behavioral Ecology and Sociobiology, 51, $262-275$

Fichtel, C., Pyritz, L., \& Kappeler, P. M. (2011). Coordination of group movements in non-human primates. In M. Boos, M. Kolbe, P. M. Kappeler, \& T. Ellwart (Eds.), Coordination in human and non-human primate groups (pp. 37-56). Heidelberg: Springer.

Fichtel, C., Zucchini, W., \& Hilgartner, R. (2011b). Out of sight but not out of mind? Behavioral coordination in red-tailed sportive lemurs (Lepilemur ruficaudatus). International Journal of Primatology, 32. 
Hawkins, C. E., \& Racey, P. A. (2008). Food habits of an endangered carnivore, Cryptoprocta ferox, in the dry deciduous forests of Western Madagascar. Journal of Mammalogy, 89, 64-74.

Isbell, L. A., Cheney, D. L., \& Seyfarth, R. M. (1990). Costs and benefits of home range shifts among vervet monkeys (Cercopithecus aethiops) in Amboseli National Park, Kenya. Behavioral Ecology and Sociobiology, 27, 351-358.

Itani, J. (1963). Vocal communication of the wild Japanese monkeys. Primates, 4, 11-66.

Jacobs, A., Maumy, M., \& Petit, O. (2008). The influence of social organisation on leadership in brown lemurs (Eulemur fulvus fulvus) in a controlled environment. Behavioural Processes, 79, 111-113.

Jacobs, A., Sueur, C., Deneubourg, J. L., \& Petit, O. (2011). Social network influences decision-making during collective movements in brown lemurs (Eulemur fulvus fulvus). International Journal of Primatology. doi:10.1007/s10764-011-9497-8.

Jacobs, A. T., Watanabe, K., \& Petit, O. (2011). Social structure affects initiations of group movements but not recruitment success in Japanese macaques (Macaca fuscata). International Journal of Primatology, 32.

Janson, C. H., \& Goldsmith, M. L. (1995). Predicting group size in primates: foraging costs and predation risk. Behavioral Ecology, 6, 326-336.

Johnson, J. B., \& Omland, K. S. (2004). Model selection in ecology and evolution. Trends in Ecology and Evolution, 19, 101-108.

Kappeler, P. M. (1991). Patterns of sexual dimorphism in body weight among prosimian primates. Folia Primatologica, 57, 132-146.

Kappeler, P. M. (1999). Convergence and divergence in primate social systems. In J. G. Fleagle, C. H. Janson, \& K. Reed (Eds.), Primate communities (pp. 158-170). Cambridge: Cambridge University Press.

Kappeler, P. M. (2000). Grouping and movement patterns in Malagasy primates. In S. Boinski \& P. Garber (Eds.), On the move: How and why animals travel in groups (pp. 470-490). Chicago: University of Chicago Press.

Kappeler, P. M. (2011). Primatological approaches to the study of group coordination. In M. Boos, M. Kolbe, P. M. Kappeler, \& T. Ellwart (Eds.), Coordination in human and non-human primate groups (pp. 223-228). Heidelberg: Springer.

Kappeler, P. M., \& Fichtel, C. (2011). A 15-year perspective on the social organization and life history of sifakas in Kirindy Forest. In P. M. Kappeler \& D. P. Watts (Eds.), Long-term field studies of primates. Heidelberg: Springer.

Kerth, G., Ebert, C., \& Schmidtke, C. (2006). Group decision making in fission-fusion societies: Evidence from two-field experiments in Bechstein's bats. Proceedings of the Royal Society B: Biological Sciences, 273, 2785-2790.

King, A. J. (2010). Follow me! I'm a leader if you do; I'm a failed initiator if you don't? Behavioural Processes, 84, 671-674.

King, A. J., \& Sueur, C. (2011). Where next? Group coordination and collective decision making by primates. International Journal of Primatology. doi:10.1007/s10764-011-9526-7.

King, A. J., Douglas, C. M. S., Huchard, E., Isaac, N. J. B., \& Cowlishaw, G. (2008). Dominance and affiliation mediate despotism in a social primate. Current Biology, 18, 1833-1838.

King, A. J., Jonson, D. D. P., \& Van Vugt, M. (2009). The origins and evolution of leadership. Current Biology, 19, 911-916.

Koenig, A. (2002). Competition for resources and its behavioral consequences among female primates. International Journal of Primatology, 23, 759-783.

Kümmeth, F., \& Heidrich, W. A. (2007). System specification for BaseStation and GPS-RF-tags, Version 0.2. Grünwald: e-obs GmbH, http://www.e-obs.de/index.html.

Lewis, J. S., Wartzok, D., \& Heithaus, M. R. (2011). Highly dynamic fission-fusion species can exhibit leadership when travelling. Behavioral Ecology and Sociobiology, 65, 1061-1069.

Li, B., Chen, C., Ji, W., \& Ren, B. (2000). Seasonal home range changes of the Sichuan snub-nosed monkey (Rhinopithecus roxellana) in the Qinling Mountains of China. Folia Primatologica, 71, 375386.

Lindburg, D. G. (1987). Seasonality of reproduction in primates. In G. Mitchell \& J. Erwin (Eds.), Comparative primate biology (Behavior, cognition and motivation, Vol. 2b, pp. 167-218). New York: Alan R. Liss.

Méndez-Cárdenas, M., Randrianambinina, B., Rabesandratana, A., Rasoloharijaona, S., \& Zimmermann, E. (2008). Geographic variation in loud calls of sportive lemurs (Lepilemur ssp.) and their implications for conservation. American Journal of Primatology, 70, 828-838.

Nunn, C. L., \& Pereira, M. E. (2000). Group histories and offspring sex ratios in ringtaild lemurs (Lemur catta). Behavioral Ecology and Sociobiology, 48, 18-28. 
Oftedal, O. T. (1985). Pregnancy and lactation. In R. J. Hudson \& R. G. White (Eds.), The bioenergetics of wild herbivores (pp. 215-238). Boca Raton: CRC Press.

Ostner, J., \& Kappeler, P. M. (1999). Central males instead of multiple pairs in redfronted lemurs, Eulemur fulvus rufus (Primates, Lemuridae)? Animal Behaviour, 58, 1069-1078.

Ostner, J., \& Kappeler, P. M. (2004). Male life history and the unusual adult sex ratios of redfronted lemur, Eulemur fulvus rufus, groups. Animal Behaviour, 67, 249-59.

Overdorff, D. J. (1993). Ecological and reproductive correlates to range use in red-bellied lemurs (Eulemur rubriventer) and rufous lemurs (Eulemur fulvus rufus). In P. M. Kappeler \& J. U. Ganzhorn (Eds.), Lemur social systems and their ecological basis (pp. 167-178). New York: Plenum Press.

Pereira, M. E. (1993). Seasonal adjustment of growth rate and adult body weight in ringtailed lemurs. In P. M. Kappeler \& J. U. Ganzhorn (Eds.), Lemur social systems and their ecological basis (pp. 205-221). New York: Plenum Press.

Pereira, M. E., \& Kappeler, P. M. (1997). Divergent system of agonistic behaviour in lemurid primates. Behaviour, 34, 225-274.

Pereira, M. E., \& McGlynn, C. A. (1997). Special relationships instead of female dominance for redfronted lemurs, Eulemur fulvus rufus. American Journal of Primatology, 43, 239-258.

Pereira, M. E., Kaufman, R., Kappeler, P. M., \& Overdorff, D. J. (1990). Female dominance does not characterize all of the Lemuridae. Folia Primatologica, 55, 96-103.

Petit, O., \& Bon, R. (2010). Decision-making processes: the case of collective movements. Behavioural Processes, 84, 635-647.

Pond, C. M. (1977). The significance of lactation in the evolution of mammals. Evolution, 31, 177-199.

Pyritz, L., \& Andrianjanahary, T. (2010). Collective mobbing of a boa by a group of red-fronted lemurs (Eulemur fulvus rufus). Lemur News, 15, 15-17.

Pyritz, L., Fichtel, C., \& Kappeler, P. (2010). Conceptual and methodological issues in the comparative study of collective group movements. Behavioural Processes, 84, 681-684.

Pyritz, L., King, A., Sueur, C., \& Fichtel, C. (2011). Reaching a consensus: Terminology used in coordination and decision-making research. International Journal of Primatology, 32. doi:10.1007/ s10764-011-9524-9.

Ramseyer, A., Petit, O., \& Thierry, B. (2009). Patterns of group movements in juvenile domestic geese. Journal of Ethology, 27, 369-375.

Rands, S. A., Cowlishaw, G., Pettifor, R. A., Rowcliffe, J. M., \& Johnstone, R. A. (2003). Spontaneous emergence of leaders and followers in foraging pairs. Nature, 423, 432-434.

Rands, S. A., Cowlishaw, G., Pettifor, R. A., Rowcliffe, J. M., \& Johnstone, R. A. (2008). The emergence of leaders and followers in foraging pairs when the qualities of individuals differ. BMC Evolutionary Biology, 8, 51.

Rasoloarison, R. M., Rasolonandrasana, B. P. N., Ganzhorn, J. U., \& Goodman, S. M. (1995). Predation on vertebrates in the Kirindy forest, western Madagascar. Ecotropica, 1, 59-65.

Rasoloharijaona, S., Randrianambinina, R., Braune, P., \& Zimmermann, E. (2006). Loud calling, spacing, and cohesiveness in a nocturnal primate, the Milne Edwards' sportive lemur (Lepilemur edwardsi). American Journal of Physical Anthropology, 129, 591-600.

Rensing, S. (1999). Immobilization and anesthesia of nonhuman primates. Primate Report, 55, 33-38.

Richard, A. (1978). Behavioral variation: A case study of a Malagasy lemur. Lewisburg: Bucknell University Press.

Richard, A. F. (1987). Malagasy prosimians: Female dominance. In B. B. Smuts, D. L. Cheney, R. M. Seyfarth, R. W. Wrangham, \& T. T. Struhsaker (Eds.), Primate societies (pp. 25-33). Chicago: University of Chicago Press.

Rodgers, A. R., \& Carr, A. P. (2002). HRE: Home range extension for ArcView. Thunder Bay: Centre for Northern Forest Ecosystem Research, Ontario Ministry of Natural Resources.

Sauther, M. L., \& Sussman, R. W. (1993). A new interpretation of the social organization and mating system of the ringtailed lemur (Lemur catta). In P. M. Kappeler \& J. U. Ganzhorn (Eds.), Lemur social systems and their ecological basis. New York: Plenum Press.

Scholz, F., \& Kappeler, P. M. (2004). Effects of seasonal water scarcity on the ranging behavior of Eulemur fulvus rufus. International Journal of Primatology, 25, 599-613.

Simmen, B., Bayart, F., Rasamimanana, H., Zahariev, A., Blanc, S., et al. (2010). Total energy expenditure and body composition in two free-living sympatric lemurs. PLoS One, 5, e9860. doi:10.1371/journal. pone.0009860.

Sorg, J. P., \& Rohner, U. (1996). Climate and tree phenology of the dry deciduous forest of the Kirindy Forest. In J. U. Ganzhorn \& J. P. Sorg (Eds.), Ecology and economy of a tropical dry forest in Madagascar (pp. 57-80). Göttingen: Erich Goltze GmbH and Co KG. 
Sorg, J. P., Ganzhorn, J. U., \& Kappeler, P. M. (2003). Forestry and research in the Kirindy Forest/Centre de Formation Professionnelle Forestière. In S. M. Goodman \& J. P. Benstead (Eds.), The natural history of Madagascar (pp. 1512-1519). Chicago: University of Chicago Press.

Stewart, K. J., \& Harcourt, A. H. (1994). Gorillas' vocalisations during rest periods: Signals of impending departure? Behaviour, 130, 29-40.

Struhsaker, T. (1967). Ecology of vervet monkeys (Cercopithecus aethiops) in the Masai-Amboseli game reserve, Kenya. Ecology, 48, 891-904.

Stueckle, S., \& Zinner, D. (2008). To follow or not to follow: Decision making and leadership during the morning departure in chacma baboons. Animal Behaviour, 75, 1995-2004.

Sueur, C., \& Petit, O. (2008a). Shared or unshared consensus decision in macaques? Behavioural Processes, 78, 84-92.

Sueur, C., \& Petit, O. (2008b). Organization of group members at departure is driven by social structure in Macaca. International Journal of Primatology, 29, 1085-1098.

Sueur, C., Deneubourg, J. L., \& Petit, O. (2010). From the first intention movement to the last joiner: Macaques combine mimetic rules to optimize their collective decisions. Proceedings of the Royal Society B: Biological Sciences. doi:10.1098/rspb.2010.2084.

Swihart, R. K., \& Slade, N. A. (1997). On testing for independence of animal movements. Journal of Agricultural, Biological and Environmental Statistics, 2, 48-63.

Tarnaud, L. (2006). Feeding behavior of lactating brown lemur females (Eulemur fulvus) in Mayotte: Influence of infant age and plant phenology. American Journal of Primatology, 68, 966-977.

Trillmich, J., Fichtel, C., \& Kappeler, P. M. (2004). Coordination of group movements in wild Verreux's sifakas (Propithecus verreauxi). Behaviour, 141, 1103-1120.

van Noordwijk, M. A., \& van Schaik, C. P. (1987). Competition among female long-tailed macaques, Macaca fascicularis. Animal Behaviour, 35, 577-89.

Watts, D. P. (1994). The influence of male mating tactics on habitat use in mountain gorillas (Gorilla gorilla berengei). Primates, 35, 35-47.

Wimmer, B., \& Kappeler, P. M. (2002). The effects of sexual selection and life history on the genetic structure of redfronted lemur, Eulemur fulvus rufus, groups. Animal Behaviour, 64, 557-568.

Wrangham, R. W. (1980). An ecological model of female-bonded primate groups. Behaviour, 75, 262-300.

Wrangham, R. W. (2000). Why are male chimpanzees more gregarious than mothers? A scramble competition hypothesis. In P. M. Kappeler (Ed.), Primate males: Causes and consequences of variation in group composition (pp. 248-258). Cambridge: Cambridge University Press.

Zuur, A. F., Ieno, E. N., Walker, N. J., Saveliev, A. A., \& Smith, G. M. (2009). Mixed effects models and extensions in ecology with $R$. New York: Springer. 